\title{
Antes del sexo. La construcción de la fantasía pornográfica en el género gonzo
}

\author{
Before sex. The construction of pornographic fantasy \\ in the gonzo genre
}

ÁLVARO MARTín SANZ*

Universidad Carlos III de Madrid

Recibido: $14 / 03 / 2020$

Aceptado: 02/09/2020

doi: https://doi.org/10.20318/femeris.2020.5766

\begin{abstract}
Resumen. La pornografía ha sido y es objeto de crítica por parte de diversas corrientes feministas debido a la cosificación y violencia a las que a menudo se somete al género femenino. Es evidente el profundo rechazo que suscitan algunas de sus representaciones debido al contenido denigrante que se produce desde una perspectiva masculina. El presente artículo parte de la hipótesis de que este tipo de contenidos inherentes a las escenas sexuales de la pornografía se encuentran ya presentes en las escenas prepornográficas que anteceden a aquellas que muestran el acto sexual. Así, se realiza una aproximación a distintas representaciones de la pornografía gonzo, también conocida como POV, para plantear cómo el elemento de cosificación del cuerpo femenino, así como las relaciones de poder hombre-mujer que se dan dentro de la secuencia pornográfica, están ya presentes en los preliminares de esta. Bajo este patrón común, se establece una división de los distintos tipos de planteamiento de los que se sirven las secuencias prepornográficas del gonzo de cara a facilitar tanto la creación del objeto pornográfico como tal, como la preparación del espectador, masculino por lo general, para el consumo de un tipo de imágenes a las que ya está habituado.

Palabras clave: pornografía, gonzo, documental, ficción, estereotipo, representación de la sexualidad.

Abstract. Pornography has been criticized by various feminist thinkers due to the objectification and violence that often the female gender suffers. Is evident the deep rejection that some of its representations cause due to the denigrating content that is produced from a masculine perspective. This article is based on the hypothesis that this type of content, inherent to the sexual scenes of pornography, is already present in the prepornographic scenes that precede those that show the sexual act. Thus, this research makes an approximation to different representations of gonzo pornography, also known as POV, to propose how the element of objectification of the female body, as well as the relations of man-woman power that occur within the pornographic sequence, are already present in its preliminaries. Under this common pattern, the article proposes a division of various types of approach that prepornographic scenes uses to facilitate both the establishment of the pornographic object and the preparation of the viewer, usually male, for the consumption of a type of images to which he is already accustomed.

Keywords: pornography, gonzo, documentary, fiction, stereotype, sexuality representation.
\end{abstract}

*alvmartinsanz@gmail.com 


\section{Introducción. Un acercamiento al gonzo}

According to usage and conventions which are at last being questioned but have by no means been overcome, the social presence of a woman is different in kind from that of a man. A man's presence is dependent upon the promise of power which he embodies. [...] By contrast, a woman's presence expresses her own attitude to herself, and defines what can and cannot be done to her. [...]. Men survey women before treating them. Consequently how a woman appears to a man can determine how she will be treated. [...]. One might simplify this by saying: men act and women appear. Men look at women. Women watch themselves being looked at (Berger, 1972: 45-47).

Estas palabras introductorias conceptualizan a la perfección, desde la óptica del arte más tradicional y heteronormativo, el tema de la representación femenina como objeto de deseo a disposición en todo momento del sujeto masculino. Esta aproximación es igualmente compartida por Laura Mulvey, para quien el placer de mirar se escinde en todo momento en dos partes irreconciliables: un masculino activo como portador de la mirada y un femenino pasivo que es observado (Mulvey, 2001: 370). Problemática que es a todas luces amplificada por un discurso pornográfico hegemónico que parece tener al hombre como consumidor preferente de sus productos. Este motivo nos lleva, antes de entrar a tratar el objeto pornográfico como tal, a denunciar ciertos prejuicios en torno a los roles sexuales que todavía hoy se mantienen. En este sentido, es igualmente necesario enunciar que si la pornografía convencional no resulta estimulante para una mujer no es en absoluto porque, tal y como afirmaba el profesor Román Gubern (2005: 18) en el año 89, el hecho de que esta sea únicamente funcional para el sexo masculino tiene que ver "con la mayor excitabilidad erótica visual del hombre en relación con la mujer [...] según una diferencia basada en sus roles biológicos." Justificación científica de carácter reduccionista que quita importancia a todo un conjunto de prácticas relacionadas tanto con la simbología como con la representación sexual, y que parece reducir para el género femenino el consumo de pornografía a lo que parece ser un indudable carácter didáctico: "El interés de la pornografía masculina para la espectadora femenina radicaría en que es contemplada como curiosidad y como eventual escuela, para comparar sus cuerpos y sus técnicas en relación consigo misma y con su propia pareja" (Gubern, 2005: 16).

Esta apología apela a la biología y excluye cualquier otra explicación por considerarla innecesaria en vez de ahondar en la complejidad de la realidad social. Se rechaza un análisis más profundo que pudiera sugerir, entre otras razones, que ese posible desinterés de la mujer hacia la pornografía bien puede venir de una mezcla de ciertos modelos de comportamiento propios del sistema patriarcal que son inculcados a través de una determinada educación de la que se siguen unos roles relacionados con la castidad y la pureza. Roles cercanos a la virtud y alejados de la corporalidad carnal, tal y como sostiene la tesis del pensador francés Pierre Bordieu en su obra La dominación Masculina (2014), en la que paralelamente a indagar en las tradicionales e inconscientes diferencias de comportamiento en función de la sexualidad, arremete contra el condicionamiento que supone nacer bajo el papel femenino. 
Así mismo, también es susceptible señalar como causa de este desinterés la expansión y magnificación de todo un continente pornográfico de corte claramente machista, a veces hasta misógino, en el que la agresión al sexo femenino puede incluso en ocasiones llegar a definirse como ofensiva para el consumidor masculino que la produce y al que normalmente va destinado. Tal es el caso expuesto por reconocidas activistas entre las que se encuentra la realizadora de cine pornográfico Erika Lust, quien en el prólogo del libro que dedica a fomentar entre las mujeres el conocimiento de la que considera buena pornografía deja claros los motivos que la llevaron a tomar un rol activo dentro de una industria tradicionalmente masculina:

I couldn't see myself in those movies-not my lifestyle or my values, and not my sexuality. They didn't portray female pleasure at all, and the women in those movies existed for one reason alone-to pleasure the men. [...] I belong to a generation whose modern, diverse sexuality is not represented in traditional maleoriented pornography. We women need to take steps now to start changing the views of sex that men have been putting out there through porn. If we don't then future generations won't have anything but that diminished, imPOVerished vision of sexuality (Lust, 2010: 3).

Lo cierto es que el tipo de imágenes que crean las películas de Lust no dejan de ser marginales muestras postpornográficas que surgen como respuesta a una serie de representaciones de producción y consumo mayoritario. Se elaboran así una serie de prácticas visuales, que hasta no hace mucho quedaban enmarcadas dentro del arte de la performance y el happening, como las realizadas por creadoras como Diana J. Torres con su pornoterrorismo (2011), que se encargan de cuestionar las representaciones tradicionales de la sexualidad. Todo ello como parte de un movimiento que surge como reacción, que es definido por otra de sus máximas creadoras como

la cristalización de las luchas gays y lesbianas de las últimas décadas, del movimiento queer, de la reivindicación de la prostitución dentro del feminismo, del postfeminismo y de todos los feminismos políticos transgresores, de la cultura punk anticapitalista y DIY (hazlo tú misma). Es la apropiación de un género, el de la representación explícita del sexo, que ha sido hasta ahora monopolizado por la industria. El postporno es una reflexión crítica sobre el discurso pornográfico (Llopis, 2010, p. 38).

En definitiva, estas corrientes responden a la pornografía mainstream al considerar que promueve un discurso que cosifica a la mujer convirtiéndola por completo en un objeto a disposición del hombre dentro de un discurso de poder tradicionalmente constituido. Tal y como la académica Linda Williams señala:

Just as westerns for so long offered myths and fantasies of America's agrarian past as told exclusively from the viewpoint of the white male settlers who exploited and overpowered the native American inhabitants , so has pornography long been a myth of sexual pleasure told from the point of view of men with the power to exploit and objectify the sexuality of women (Williams, 1999: 22). 
Más allá de estas teorías, definir la pornografía parece hoy en día, dada la infinitud de variantes y temáticas que engloba el término, una misión casi imposible debido a la gran permeabilidad del concepto (Boyle, 2006: 6). Así pues, nos encontramos con toda una colección de adjetivos transformados en géneros que normalmente permanecen en su idioma original dado el hecho de que las principales webs que ofrecen este contenido son extranjeras: couple, bondage, amateur, voyeur, footfetish, oral sex, milf, teen, threesome, sex at work, gangbang, orgy, y un larguísimo etcétera que parece calificar de manera inevitable el resultado que podemos esperar encontrar dentro de cada temática. Se producen así innumerables tipos de imágenes pornográficas que, sin embargo en consonancia con DeKeseredy, dadas sus condiciones de producción, acaban teniendo en común dos hechos: "females are characterized as subordinate to males and the primary role of actresses and models is the provision of sex to men" (DeKeseredy, 2015: 6).

Estas características pueden verse en el estilo/genero por antonomasia del porno digital, el gonzo, también llamado porno en primera persona o POV (Point of View), una suerte de neorrealismo del sexo basado por encima de todo en un estilo directo y sin cortes. Una pornografía que deja de lado las narraciones y tramas tradicionales del género para centrarse de forma exclusiva en el acto sexual, el cual acaba ocupando la práctica totalidad de la obra (Biasin, Zecca, 2009: 143). La terminología alude directamente al periodismo gonzo, género popularizado gracias al escritor Hunter $S$. Thompson en el que el reportero forma parte del evento que tiene lugar. Así pues, la pornografía gonzo huye de complejas puestas en escena orquestadas por un equipo de realizador y operadores de cámara para que, claramente influenciada por la pornografía amateur a la que a menudo trata de imitar, sea el actor masculino el encargado de filmar los distintos actos sexuales, eliminándose así la separación tradicional entre cámara, director e interprete al englobar esta última figura a las otras dos.

El espectador es por lo tanto quien toma el rol del actor al aceptar su visión como si él mismo hubiera grabado la secuencia. Como parte de esta identificación es común que la mujer se dirija a menudo al objetivo de la cámara (rompiendo la cuarta pared y transgrediendo así una de las principales normas del lenguaje cinematográfico tradicional) para provocar una reacción directa en el espectador. Este recurrente truco forma parte de un estilo que implica una realización más fácil, rápida y barata que una producción pornográfica tradicional, y que en palabras del productor estrella José María Ponze "ha limitado completamente el lenguaje del porno. Sobre todo porque se ha masificado" (Costa, 2006: 105). Y es que, además, de cara a lograr una mayor sensación de realismo, se suele prescindir de los típicos cortes que acompañan a la cinematografía de montaje. Por lo general, el gonzo se graba en una única toma que se encarga de documentar toda la acción sexual de la manera más fidedigna posible. Tal y como indican Maina y Zecca:

Besides giving the impression of an uninterrupted and haptic flow of images, the use of long takes also plays an important role in the strategies of signification enacted by gonzo, in that it certifies the authenticity of the sexual acts performed during the scenes, even those considered most extreme" (Maina, Zecca, 2016: 342). 
Es debido a la alta intensidad y a la autenticidad con la que se reflejan prácticas de lo extremo que se muestran en este tipo de pornografía que "[m]any scholars and commentators identify the absence of narrative and the accent on extreme sexual acts as the main features of gonzo, thereby adopting a definition primarily based on content." (Maina, Zecca, 2016: 337). Así parecen conceptualizarlo tanto Dines como DeKeseredy. Para el primero, el gonzo "depicts hard core, body-punishing sex in which women are demeaned and debased" (Dines, 2010: xi), mientras que para el Segundo, "a common feature of new pornographic videos is painful anal penetration as well as brutal gang rape and men slapping or choking women or pulling their hair while they penetrate them orally, vaginally, and anally" (DeKeseredy, 2015: 6). Estos distintos grados de violencia tienen una correlación para no pocos estudiosos con el maltrato hacia la mujer en la vida real (DeKeseredy, Hall-Sánchez, 2016; Shope, 2004; Harmond, Check, 1989). Para C. MacKinnon (1987: 171), la pornografía "sexualiza la violación, los golpes, las agresiones sexuales, la prostitución y el abuso de los niños, y por lo tanto los celebra, promueve, autoriza y legitima". Susan Brownmiller (1981: 391) desarrolla también esta idea de la pornografía como canalizadora de una violencia real.

Por otra parte, otras tantas corrientes de pensamiento traten de desmontar esta conexión (Purcell, 2012: 22). Ruwen Ogien por ejemplo se opone a esta ideología analizando la campaña llevada a cabo por el gobierno francés en el año 2002 en contra de la difusión de contenido pornográfico por televisión, campaña basada en lo que el autor denomina falacia monkey see-monkey do. El mono imita lo que ve, y por tanto la pornografía es la antesala directa de la acción (Ogien, 2005). Lejos de indagar sobre esta cuestión, no parece haber discusión en torno a la violencia de ciertas prácticas contenida en multitud de escenas. Violencia que se sustenta sobre unos roles de género determinados que sirven de soporte para el desarrollo de todo un conjunto de actitudes ofensivas hacia el sexo femenino. Estos arquetipos, perfectamente reconocibles y presentes en todo momento, han sustituido las narrativas tradicionales que se encargaban de definir tanto el poder masculino como el sometimiento femenino. Siguiendo a Purcell:

Contemporary heterosexual pornography no longer relies on narrative constructs to convey violence and coercion, and the encounters on-screen seldom assume the appearance of sadomasochistic role-playing: Because phallic-centered male bodies so consistently assume dominance and because female bodies so consistently retreat into deference and submission, the assumed "roles" are far too biologized and stable to feel chosen and mutable. [...] what will happen and how it will happen seem predetermined and inevitable rather than spontaneous. The pornographies that sell best to heterosexual men build masculine dominance into the aesthetics, techniques, and language of each sexual encounter (Purcell, 2012: 137).

Así pues, el objetivo del presente artículo es realizar un análisis de los contenidos y representaciones prepornográficas presentes dentro del método de producción POV para demostrar cómo el elemento de cosificación del cuerpo femenino forma una representación del deseo que se crea necesariamente antes de que empiece el verdadero objeto pornográfico como tal. De esta forma, se posibilita no sólo la aparición de este, sino también la preparación del espectador ante un determinado consumo de imágenes pornográficas 
a las que, por otra parte, ya está habituado. Para ello, la metodología establece un análisis de contenido sobre una seleccionada muestra de escenas pornográficas que reflejan de forma clara y concisa algunas de las principales estrategias comunicativas que desarrolla el gonzo basándose en distintos tipos de representaciones femeninas.

El criterio seguido a la hora de configurar la muestra parte de tres condiciones: en primer lugar, que sean escenas lo suficientemente representativas a nivel formal de los distintos planteamientos pornográficos que se estudian, en segundo lugar, que cuenten con más de un millón de visualizaciones en las principales webs de consumo pornográfico (algunas exceden por mucho esta cantidad), y por último, que estén protagonizadas por intérpretes lo suficientemente conocidas por el público, es decir, que las actrices estén consolidadas dentro de la industria, y que, por consiguiente, puedan ser incluidas dentro de la categoría de pornstar o estrella del porno.

Se realiza por lo tanto un análisis textual de cada uno de estos tipos de estructuras presentes de forma genérica dentro de la construcción del objeto pornográfico atendiendo a la narrativa que presentan. Así mismo, se analiza el filme de ficción After Eden (Hans Christian Berger, 2015) por ser un buen ejemplo de las fantasías iniciales que recrean las obras pornográficas en sus primeros instantes que además muestra la futilidad y falta de sentido de estas escenas cuando son descontextualizadas de su propósito primario.

\section{Fantasías en torno a la feminidad: de la estrella provocadora a la desconocida sobornable}

Resulta interesante seguir la división del gonzo que realizan Maina y Zecca al separar la pornografía contemporánea en dos modos: por un lado el modo espectáculo y por el otro el documental. Así, en el primer tipo de imágenes:

there is in fact a spectacle mode in which the spectator perceives the [sexual performance] as a spectacle. [...] It creates a spectacular space that presents itself as intentionally aimed at delivering a show rather than at creating a plausible world to believe in (Maina, Zecca, 2016: 344).

Mientras que en el segundo, se busca camuflar el constructo presentándose las imágenes como

primarily as documentation of actual events, happening for real outside the domain of representation that is, sexual acts, no matter how hyperbolic, which could have happened even if there was no one there to record them. In this sense, gonzo can be considered as the feigned documentation of a staged reality (Maina, Zecca, 2016: 345).

Sobre esta clasificación, considero necesario incidir en el hecho de que no estamos hablando de compartimentos estancos, y que si bien el porno espectáculo puede presentarse por sí mismo de forma independiente como una fantasía increíble, a menudo parte de 
sus postulados son presentados dentro de la pornografía documental. De esta forma se trata de conciliar el documento de la realidad con la fantasía de todo lo que puede imaginarse.

De cara a analizar el contenido de las secuencias sexuales, cabe señalar que, por lo general, ambos modos operan dividiendo la escena en dos partes claramente diferenciadas: una primera, que podríamos llamar la de preparación a la secuencia puramente sexual, y una segunda que contiene el objeto pornográfico en sí. A mayores, en no pocas secuencias, estas dos partes son complementadas por una tercera que tiene lugar justo después de que concluya el acto sexual. Estas escenas posteriores recuperan un formato de entrevista para interrogar a los actores y a las actrices, especialmente a ellas, acerca de sus impresiones sobre la escena que acaban de protagonizar. Esta estructura se repite de forma constante dentro del gonzo con multitud de configuraciones distintas en función del contenido de la escena.

Así pues, sobre la preparación de la secuencia sexual, entendida esta como la preparación del espectador ante lo que va a presenciar, encontramos dos tipos de planteamientos claramente diferenciados que sin embargo convergen en multitud de ocasiones. En primer lugar, se encuentran aquellas escenas que aquí definiremos como de videoclip, las cuales giran en torno a imágenes eróticas y sexuales, de mayor o menor tono, de la actriz que va a protagonizar la secuencia. Estas imágenes suelen ir acompañadas por una sintonía musical que se encarga de poner sonido a imágenes en las que la actriz, normalmente en ropa interior desde el inicio, acostumbra a mostrar sus atributos corporales a la cámara rompiendo la ilusión de la cuarta pared. Así, como parte de un juego personal con la cámara, con un conjunto de gestos provocativos va desnudándose y mostrando más partes de su cuerpo, manteniendo distintas posturas que permitan contemplar mejor su anatomía o jugando ligeramente en las escenas más pornográficas con juguetes sexuales o aceitosos lubricantes. Todo ello como parte de una coreografía de distintos movimientos y posiciones que se sirve del montaje de tomas variadas para, con ayuda normalmente de la música, dar un cierto sentido de ritmo y look de videoclip musical al resultado final. Estas secuencias iniciales son las que fijan el tono de pornografía como espectáculo, como fantasía y ensoñación, tal y como ciertos efectos de brillo insertados en posproducción parecen indicar, de toda la secuencia sexual posterior.

Este tipo de introducción de la escena pornográfica funciona a la manera de una suerte de presentación de la actriz desde un punto de vista puramente físico, centrándose en su anatomía y a menudo buscando realzar y magnificar sus atributos mediante la captura de primeros planos o la utilización de objetivos angulares. Se empieza así a elaborar una objetificación como forma de violencia contra la mujer (Attwood, 2004: 2) que además es recurrente en buena parte del cine pornográfico, una "characteristic reduction of women to passive, perpetually desiring bodies -or bits of bodies- eternally available for servicing men" (Segal, 1992: 2). Cabe señalar también que por lo general las actrices que protagonizan estas secuencias son, si no estrellas de la industria, al menos sí caras conocidas por gran parte del público, que ya las ha visto en acción y ya sabe cómo son los cuerpos desnudos que quiere desear.

Las escenas de presentación con formato de videoclip suelen darse en su gran mayoría dentro del gonzo de producción estadounidense, enclavándose en escenarios que 
reflejan la opulencia cumplida del sueño americano: grandes mansiones, piscinas privadas, coches de lujo o jardines paradisiacos. Así pues, la "mujer perfecta" cosificada se une a esta enumeración como un elemento más. Se sigue de esta forma el espíritu Playboy de la exhibición de la interioridad privada mediante la teatralización del espacio (Preciado, 2010: 72), en donde el cuerpo femenino queda reducido al principal objeto de deseo de una representación de distintas fantasías consumistas dentro de una estrategia de venta de una imagen de éxito que se encarga de alternar distintas combinaciones de estrellas femeninas de cine pornográfico y pomposos escenarios:

The contemporary pornography cinema industry is involved in branding strategy; that is, it is trying to capitalize its resources (namely economic, aesthetic, structural and human resources) in order to provide to its consumers a wide range of products able to transform the economic profits achieved into cultural values (quality, authenticity and diversity) (Biasin, Zecca, 2009: 136).

El segundo tipo de planteamiento de estas escenas previas lo definiremos como de calentamiento. Al contrario que el anterior, este está presente tanto en producciones norteamericanas como en europeas. Se renuncia en él a las intenciones de idealización sobre el entorno y sobre las cualidades físicas del cuerpo femenino para presentar en cambio una entrevista a la actriz o actrices (en menor medida a los sujetos masculinos) que van a protagonizar la secuencia pornográfica. De esta manera, lejos de reflejar la efervescencia de la sexualidad desde el primer momento, tal y como se hace en las presentaciones de estética de videoclip, el tratamiento resulta mucho más directo y natural. Así, se busca un efecto de realidad que cumpla la promesa de autenticidad que supone la pornografía (Black, 2002). Para ello, lejos de una planificación profesional, la cámara en mano es normalmente acompañada por actores no profesionales y escenarios no muy elaborados (Paasonen, 2006: 413). Además, en consonancia con el espíritu del gonzo, se intentan minimizar los recursos cinematográficos, por ejemplo evitando cortes entre esta escena previa y la propia escena sexual que la sigue. Este tipo de enunciación sirve para presentar tanto a actrices consolidadas y conocidas por el público dada su carrera previa, como a nuevas mujeres que están comenzando en la industria. La idea es, ante todo, establecer un determinado ambiente que propicie la transición al sexo, "once the scene is set, pornography can get down to real action" (Kuhn, 1994: 45).

Dentro de la concepción del gonzo como espectáculo este tipo de escenas suelen estar relacionadas con la presentación del "reto" o "desafío" que la actriz o actrices van a protagonizar. Es decir, el concepto de espectáculo puede derivar de las imágenes sexuales (forma de videoclip), o de una narrativa previa en torno a las prácticas que se van a realizar. Se establece de esta forma un show en el que lo espectacular surge de la combinación de la exageración y la realidad (Díaz-Benítez, 2013: 95). Este espectáculo comienza con toda una serie de preguntas acerca de dicha práctica sexual inusual: si se ha realizado anteriormente, si existe cierto nerviosismo, así como una serie de detalles que se mencionan sobre las particularidades de esta (cuantas figuras masculinas van a estar presentes, cual es el 
tamaño del miembro viril del actor que va a compartir la escena...). La pornografía, ya desde las escenas de su concepción, cumple la teoría enunciada por Michela Marzano (2006: 13) de que "vacía el misterio de la sexualidad de todo contenido", borrando la subjetividad y reduciendo a los personajes a productos de consumo. Podemos ilustrar como ejemplo de este planteamiento una secuencia de Facialized 2 (Mason, 2015) en la que la actriz Mia Malkova muestra los momentos previos a participar en un gangbang:

At the beginning of the first episode, the female talent Mia Malkova is sitting in the backseat of a car, chatting with the director Mason. Although we do not see Mason, we hear her talk at length with Mia, asking her whether she has ever performed in a blowbang involving multiple facials, whether she is nervous or excited about that, and so on. The sexual action starts abruptly after a quick dissolve (Maina, Zecca, 2016: 344).

Otro ejemplo de este tipo de secuencia lo refleja una célebre escena de la serie Fuck Team Five de Bangbross en donde vemos, de nuevo en el interior de un coche mediante un plano entero frontal, a tres estrellas mundialmente conocidas del cine para adultos ligeras de ropa: la norteamericana de origen cubano Diamond Kitty, la colombiana Abella Anderson y la española Rebeca Linares. Las tres mujeres, que en un principio fingen desconocer el tipo de escena que van a filmar, muestran su sorpresa cuando el cámara les anuncia que van a acudir a un casting colectivo de un grupo de hombres que busca dar sus primeros pasos en la industria del porno. Es en ese momento en el que se impulsa su coqueteo inicial con la cámara, planeando cómo "torturar" a los jóvenes aspirantes, bromeando acerca de la impotencia que suelen causar los nervios, o recordando escenas y prácticas sexuales que han realizado en el pasado. Acto seguido, sin mucho pretexto de por medio y por exigencia del hombre con el que conversan, muestran sus pechos a cámara dejando que la imagen capte todo tipo de detalles antes de darse la vuelta y mostrar el resto de su anatomía, aunque sin llegar a enseñar órganos genitales. Así, entre risas y bromas sexuales, prosigue brevemente la conversación acerca de la impresión que van a causar en el grupo de hombres con el que van a compartir escena. Es gracias a un rápido fundido que la imagen da paso a la habitación en la que estos están esperando su llegada.

Esta primera parte de la secuencia, que antecede a la muestra explícita del acto sexual que tiene lugar después, sirve principalmente para construir el objeto de deseo en torno al cuerpo femenino de las actrices. Este efecto se busca a través de una doble vía, en primer lugar por medio de una actitud lasciva y abierta de las intérpretes, quienes se recrean comentando con todo detalle y entre risas parte de sus experiencias sexuales, y en segundo lugar a través de la exposición directa de sus cuerpos. En estos instantes la interacción de las mujeres no se produce con el hombre que las filma, sino con el objetivo de su cámara. De esta forma, a través de la mirada de las actrices mientras muestran sus atributos sexuales se empiezan a representar a sí mismas en escena como fantasías pornográficas (Žižek, 1997: 178-179). La pornografía comienza así a generar el deseo sexual en la masculinidad hegemónica que, siguiendo a Mónica Alario Gavilán (2018: 67), produciría el consumo de prostitución en los varones. 
Para que una representación de este tipo tenga éxito y logre su cometido de construir el objeto de deseo, en este caso se parte del glamour propio de la actriz, que se encasilla en su personaje de estrella pornográfica desde el primer momento mediante una vestimenta escasa, ajustada y sexual, y de una conversación que refleje su gusto por el sexo, sus ganas de tenerlo (McNair, 2002: 40), su predisposición a realizar cualquier práctica, y detalles del espectáculo sexual que va a realizarse. Este acto se presenta como un desafío, en ocasiones también a nivel biológico, de las normas dictadas por la sexualidad tradicional, de sus "assumptions, beliefs, prejudices, rules" (Weeks, 2003: 5). Y es que el gonzo concebido como espectáculo suele tratar a menudo distintas prácticas como "anal gaping", "ass-tomouth", "anal creampie", "throat fucking", “cum swapping”, "bukkake”, "gangbang”, "multiple swallows" (Maina, Zecca, 2016: 340). Imágenes sexuales que pudieran ser incluidas dentro de lo perverso debido a que o bien

extend sexual practices beyond those regions of the body conventional designated as appropriate (that is the genitals of either sex), or linger over activities that may be proper if they ultimately lead to genital sexuality [...] but which become perverse if they remain as ends in themselves" (Weeks, 2003: 67).

En este tipo de escenas, el gonzo trata por lo tanto de buscar el atractivo de la perversidad de una serie de tabús que se salen de lo habitual explayándose en primer lugar en detalles acerca del contenido de estas prácticas.

Pornography is seductive because it represents the secrets of private sexual desire in all their taboo-breaking, transgressive exoticism. It is, by definition, a violation of public morality and taste - an affront to community standards in the sphere of sexual representation, whatever they may be (McNair, 2002: 42).

Motivo por el que se incide en esta recreación de todo lo que supone para la actriz la práctica-espectáculo que va a acontecer, incidiéndose en la cuantificación de la escena (número de hombres o de prácticas diversas), y centrándose estos momentos pre-sexuales en realizar una suerte de video-confesión de la mujer (o mujeres) que va a protagonizar el coito. La mujer se muestra predispuesta y hasta excitada por realizarla, abriendo además su intimidad al espectador para desvelar toda una serie de secretos personales relacionados con dicha práctica sexual. Así es como desde estos primeros momentos la obra presenta "its sexual objectification of women viewed as the purest manifestation of predatory male voyeurism" (McNair, 2002: 23), cuyo deseo por ver se extiende así mismo hacia el saber que antecede a la pura acción que centra la pieza. Tal y como ejemplifica la confesión de la actriz californiana Gia Love en una de sus recientes escenas para Evil Angel:

Hi, I'm Gia Love and today I came to Evil Angel cause I'ts always been my fantasy to get fucked by five guys at the same time. This is my first double penetration, double anal gangbang and I'm gonna attempt to do all those things today in my video. I've already been preparing all day and I'm super excited. 
La segunda configuración de la pornografía gonzo, la puramente documental, muestra una serie de cambios con respecto a las presentaciones que suelen contener las imágenes del porno-espectáculo. Así pues, lejos de buscar desde el primer momento de la secuencia la magnificación de la escena que va a tener lugar después, bien mediante planos musicales de la actriz protagonista o bien mediante una enumeración de los actos más o menos insólitos que se van a realizar posteriormente, el acercamiento privilegia la grabación de un documental del presente. Se transmite al espectador la sensación de que está siendo informado de eventos reales como parte de un modo definido "in terms of the real (as opposed to fictional) status of its enunciator" (Buckland, 2003: 89). Es debido a ello que se emplean una serie de técnicas cinematográficas (también por lo general presentes en buen número de presentaciones de porno-espectáculo) tales como grabar sin cortes con una única toma, la utilización de la cámara en mano, iluminación natural, la visión subjetiva, así como toda una serie de recursos que alejan la filmación de las complicadas puestas en escena que tiene el cine narrativo para acercarla al hecho documental. Se crea, de esta manera, un efecto de autenticidad que "encourages viewers to read what they see as the factual recording of a sexual performance-rather than as a fictional story" (Maina, Zecca, 2016: 344).

Contrariamente al videoclip de presentación, en donde la archiconocida estrella pornográfica muestra una vez más sus atributos, el formato de entrevista de calentamiento sirve también como carta de presentación para la actriz desconocida, esa que está dando sus primeros pasos dentro de la industria pornográfica y desea darse a conocer, bien mediante su primera escena bien mediante una nueva práctica. Como ejemplo del contenido de estas representaciones es posible observar la secuencia que presenta el "desvirgamiento anal" de la actriz española Noemi Jolie para la productora Cumlouder. Con una cercanía física con respecto a la cámara, la actriz, que aparece sentada sobre una cama, habla entre risas con el actor, y cámara, sobre la práctica que va a llevar a cabo:

-Hola, ¿qué tal chicos de Cumlouder?

-Bueno, que venimos aquí a hacerte una visita.

-Venis aquí a hacerme una visita, creo que me vais a petar el culito... y bueno, no me hace mucha gracia...

- ¿Ya te lo han chivado?

-Me lo han chivado, pero lo voy a probar, a ver qué conseguimos.

- ¿Nunca te habían petado el culo?

-Dos veces pero hace mucho tiempo y como lo tengo tan chiquitito pues hay que volver a abrirlo otra vez.

$-i \mathrm{Si}$ ?

-Sí. No sé si costará mucho o poco... seguro que el que penetra va a disfrutar ¿eh? Pero yo no tanto...

Sexo no sólo centrado en el placer de él, a pesar del dolor que ya anticipa va a tener ella, sino también basado en una configuración de ficción, que, a pesar, de estar grabada de una forma documental, muestra dos arquetipos clásicos: dominador y dominada (Prada Prada, 2010: 14). Por un lado, el hombre, que domina el planteamiento de la escena, 
dirigiéndose a la actriz con una voz firme y un lenguaje directo, y por el otro, la mujer, que buscando complacer al actor que graba a la cámara, y al espectador no puede más que intercalar pequeñas risas en un discurso que, si bien mantiene el elemento erótico y sexual, no llega al mismo nivel de explicitud (él dice culo, ella culito), mostrándose además como dispuesta al sexo por doloroso que pueda llegar a ser. Este dolor de la actriz, tal y como ella misma asegura, va a causar mucho placer al actor, de quien, siguiendo los parámetros estilísticos del POV, tan solo vamos a ver los órganos sexuales en busca de una identificación con los del espectador. Así pues, si el actor va a disfrutar más de la escena, el espectador a su vez también, se produce por lo tanto una suerte de placer sexual delegado:

Cuando el espectador se identifica con el principal protagonista masculino, está proyectando su mirada sobre la de su semejante, su suplente en la pantalla, de modo que el poder del protagonista masculino que controla los acontecimientos coincide con el poder activo de la mirada erótica, produciendo ambos una satisfactoria sensación de omnipotencia (Mulvey, 2001: 371).

Siguiendo a Linda Williams (1999b: 65), una narrativa como esta evidencia la imposibilidad de representación del deseo femenino dentro de la pornografía hegemónica. El dolor de ella se asocia al placer de él, se manda un mensaje de agresión masculina y subordinación sexual femenina que en cierta forma erotiza tanto la degradación de la mujer como la brutalidad masculina (Crabbe \& Corlett, 2010: 3). La mujer se convierte así en un medio para que el varón afirme su masculinidad y obtenga placer sexual (Alario Gavilán, 2018: 70), estando estas funciones relacionadas en muchos casos en los que "es precisamente el dominar a las mujeres lo que les produce placer sexual" (Alario Gavilán, 2019: 57).

La pornografía se vuelve entonces una forma de doble dominación: discursiva y material (Braidotti, 2002: 29). Una escena narrativa como esta constata que la explicitación de la ideología de la supremacía masculina (Malem Seña, 1992: 190) antecede al contenido pornográfico. Ya desde estos primeros momentos la pornografía desvela su tema como género en torno al poder masculino (Dworkin, 1981: 24). Son estas las características que nos devuelven a John Berger y a los comienzos del mensaje de identificación masculina contenido en la pornografía:

There was a special category of private pornographic paintings (especially in the eighteenth century) in which couples making love make an appearance. But even in front of these it is clear that the spectator-owner will in fantasy oust the other man, or else identify with him. By contrast the image of the couple in non-European traditions provoques the notion of many couples making love (Berger, 1972: 56).

De esta forma, tal y como se puede ver, el planteamiento inicial de la escena suele presentar un pequeño diálogo preparado en mayor o menor medida que, gracias al estilo gonzo, puede mantener la ilusión de verdad al ser presentado con parámetros de obra documental. Es en este diálogo en el que las configuraciones del género se llevan al extremo de cara a construir un erotismo pre-coital dirigido al espectador masculino. Siguiendo 
a McNair, ellos son presentados como fuertes y depredadores, mientras que ellas como emocionales, débiles y sumisas (McNair, 2002: 2). Además, las ficciones creadas por la pornografía contemporánea a menudo van más allá, gracias a los parámetros estilísticos del cine documental que funcionan como garantes de realismo, al concebir todo tipo de narrativas en las que la mujer necesita la ayuda del hombre ${ }^{1}$. Así tenemos,

other gonzo forms that employ a conventional narrative frame in which a woman (or more woman) is lured into having sex in Exchange for something (money, a modelling job, a taxi ride, etc.) generally finding out that she will never receive what was promised (Maina, Zecca, 2016: 346).

De esta forma, la pornografía se centra en las múltiples variantes del poder masculino con respecto a la indefensión femenina. La pornografía

Construye a las mujeres como cosas para uso sexual y construye a los consumidores para que deseen desesperadamente a mujeres que desean desesperadamente la posesión y la crueldad y la deshumanización. La propia desigualdad, el propio sometimiento, la propia jerarquía, la propia objetificación, con el abandono estático de la determinación personal, es el contenido aparente del deseo y el carácter deseable de la mujer (MacKinnon, 1995: 245).

Este tipo de ficciones, que juegan con el estilo documental, en ocasiones muestran la ironía de sus proposiciones al incluir el fake en su título, tal y como es el caso, entre otras, de las series Fake Agent o Fake Taxi (Brodesco, 2016: 367). Falsedad que implica que se ofrece a los espectadores una comunicación mentirosa (Jost, 2003: 55). A pesar de ello, y por muy inverosímil que parezca en ocasiones, la construcción de una narrativa que se sustenta en la pretensión de realidad adquiere múltiples formas y está presente en una gran mayoría de las escenas pornográficas Gonzo. Escenas como las que popularizaron al auto apodado rey del porno freak, Torbe, quien con su serie de videos titulada Las pilladas de Torbe, seguía las formas estilísticas del videoreportaje para reflejar la extrema facilidad con la que cualquier mujer es susceptible de ejercer la prostitución a cambio de la suma adecuada de dinero. Así pues, la estructura básica de esta serie de escenas presenta a Torbe armado con una video cámara grabando en primera persona en algún lugar público como la calle, el metro o un centro comercial. No tarda en encontrar a su actriz, y, fingiendo desconocimiento mutuo, se entabla entre el realizador y la chica una breve conversación en la que al poco de haberse realizado la presentación, llega el ofrecimiento económico.

Como hecho reseñable cabe destacar que, dentro de esta serie al igual que dentro del porno gonzo mayoritario y al contrario que en las concepciones clásicas de la pornografía, lejos de representar en todo momento la perfección del cuerpo femenino de formas perfectas, cualquier mujer por el hecho de serlo, sin importar su condición o edad, es sus-

\footnotetext{
${ }^{1}$ Una excepción a esta corriente la formarían toda una serie de escenas que podemos denominar como de favor familiar. En ellas, normalmente la "madrastra" o la "hermanastra" del actor que filma se ofrecen para satisfacer las necesidades sexuales de este.
} 
ceptible de ser convertida en objeto sexual. Se abre esta pornografía, que se encuentra en la frontera de lo amateur y lo profesional, a llevar "the sexual representation of male and female bodies to a much wider variety of age, race, body types, and range of features in regards to cultural norms of beauty tan previous forms of porn" (Lehman, 2006: 13). Rasgo este que comparte con nuevas pornografías feministas como la creada por la cineasta sueca Erika Lust (Martín Sanz, 2018). En el caso de Torbe, no hay por lo tanto límites para la sexualización de la mujer. Hecho que quiere exponer el realizador con su propuesta, cuyo título hace referencia al hecho de que una mujer, a menudo con pareja, sea "pillada" vendiendo su cuerpo. Valga como ejemplo de ello el debut de la actriz Zenda con el productor bilbaíno, quien la detiene de forma súbita mientras esta camina por la calle.

-Hola, ¿qué tal? ¿Te puedo hacer unas preguntas así rápido? [...] Estoy haciendo una encuesta sobre el amor. ¿Tú estás enamorada ahora mismo?

-Sí.

$-¿$ Mucho? ¿Poco?

-Bastante.

Esta conversación acerca de la privacidad emocional no tarda en subir de tono con una serie de preguntas y apelaciones en torno al sexo y a la fidelidad para acto seguido hablar de las necesidades económicas de la joven antes de terminar preguntando:

-A ti alguna vez te han preguntado por la calle o por algún sitio si harías sexo a cambio de dinero

- No...

-Osea, si te lo preguntaran, ¿cuánto es la cantidad? a ver, por ejemplo...

-Cuatrocientos, quinientos euros, una cosa así...

$-¿$ Cuatrocientos, quinientos euros?

-Sí

¿Y nunca te lo han ofrecido no?

-No.

-Osea que si te lo ofrecen tú lo harías...

-Hombre, depende, por el dinero, está muy bien. Además, si me pagan por hacer algo que me encanta. ¡A ver si llevo perdiendo dinero muchos años!

-Pues ¡qué casualidad!, ¡porque yo soy esa persona que te va a dar ese dinero!

Ambos dos se echan a reír antes de que Torbe le ofrezca un pequeño fajo de billetes añadiendo "luego lo cuentas". Desde ese momento, al igual que en las anteriores escenas, la conversación adquiere una dinámica de poder basada en un juego verbal en el que el realizador se sitúa por encima de la chica ordenando y dirigiendo las distintas acciones. "Me he fijado que tienes unos pechitos muy sugerentes, ¿podríamos ir al final del callejón y me los enseñas un poco?" La joven actriz se muestra dispuesta a todo, siguiendo así mismo el retrato de hambrienta sexual del arquetipo de estrella porno mencionado con anterioridad. "When it comes to sex, she is up for anything. Whether she is active or pas- 
sive, assertive or submissive, she does not set boundaries and she does not shy away from "dirty"acts". (Purcell, 2012: 138). Sin embargo, a pesar de ello, Zenda admite que, dentro de su vida de estudiante, es la primera vez que realiza una acción así, encajando a su vez en el perfil de "vecina de al lado" o playmate. Figura inofensiva que en parte crea su atractivo en una absoluta ausencia de cualquier tipo de amenaza. En palabras de Russ Miller: "Las playmates eran chicas encantadoras y limpias, nada había que temer al seducirlas" (Miller, 1984: 57).

\section{Ficcionalizando los preliminares. El caso de After Eden (2015).}

Dentro de estas ficciones previas al acto sexual que funcionan como escenas de calentamiento ocupan un lugar destacado los castings profesionales. De nuevo grabados siguiendo las máximas del estilo gonzo, se permite en ocasiones la utilización del trípode durante sus primeros instantes para acercar el resultado final al de los videos de entrevistas de trabajo o castings corrientes de intérpretes. Este tipo de secuencias plantean la valoración de una candidata a actriz, tanto por parte del realizador que firma la pieza como por parte del espectador del video final, por medio de una entrevista verbal y de una exposición a cámara de sus atributos físicos. Finalmente, estos hechos son complementados por una secuencia sexual en la que el realizador copula con la aspirante para terminar emitiendo un veredicto acerca de las posibilidades de la mujer. De esta manera, lo que empieza siendo un casting al uso, acaba siendo una secuencia pornográfica por derecho propio.

Conectando con esta corriente, viene al caso tratar el film canadiense After Eden (2015), estrenado en la sección Nuevos Realizadores del 63 Festival de Cine de San Sebastián, supone el debut en la dirección de Hans Christian Berger, quién además escribe esta cinta centrada en la rutina diaria de una actriz de éxito de cine para adultos, interpretada esta por la actriz pornográfica Alyssa Reece. La obra, que busca ser un retrato del voyeurismo pornográfico, es el resultado de quitarle el sexo a la pornografía para descubrir en sus secuencias preparatorias una insulsa ficción representada como un documental. Es al omitir las secuencias sexuales que la película pone el énfasis en una serie de arquetipos planos que ni aportan nada ni conducen a ninguna parte.

Así pues, emulando el género del casting pornográfico, ampliamente difundido dentro del gonzo, el film comienza con una larga escena filmada con cámara en primera persona en la que la joven protagonista es entrevistada por un productor de cine pornográfico. Siguiendo a una serie de preguntas personales que están presentes en la práctica totalidad de este tipo de secuencias (¿cuántos años tienes? ¿de dónde eres? ¿por qué quieres hacer porno? ¿tienes pareja? ¿qué piensa de que quieras entrar en el porno?), el realizador demanda a la protagonista irse quitando progresivamente la ropa mientras narra algunas experiencias sexuales pasadas. La muestra del desnudo de la actriz no es aquí, al contrario que en la pornografía gonzo de estilo videoclip concebida como espectáculo, una orgullosa exhibición de unos atributos ya mostrados con anterioridad. Al contrario, el desvelo se produce, al igual que en más videos de este estilo, con una cierta timidez que 
suele ir acompañada por la reafirmación del valor de dichos atributos por parte del personaje masculino que filma la secuencia, encargado de valorar lo que está viendo mientras la actriz se limita a seguir sus indicaciones.

Así, mensajes como "bájate el pantalón" o "quítate el sujetador" "suggest that her job is to obey, his to demand and instruct" (Purcell, 2012: 137). La generosidad con la que poco a poco la actriz va mostrando sus atributos a la cámara es solo parte del motor que activa de manera progresiva el deseo del espectador, personificado una vez más en el actor que graba. "El hombre no sólo controla la fantasía de la película, sino que surge además como el representante del poder en un sentido nuevo: como portador de la mirada del espectador" (Mulvey, 2001: 371). Siguiendo su rol activo, la figura masculina se toma la libertad de ir más allá recurriendo al sentido del tacto para, a medida que la actriz va fingiéndose más cómoda con la situación, traer a colación de una manera explícitamente verbalizada la propuesta sexual. La única diferencia que mantiene After Eden con la pornografía gonzo es que en el momento en el que va a comenzar la escena puramente sexual, un corte a negro traslada al espectador a una ficción tradicional revestida de un estilo moderno basado también en un estilo de cine documental.

Es gracias a un corte posterior que el espectador vuelve a adentrarse en el falso reino de la no ficción para presenciar, de nuevo en primera persona, otra audición protagonizada por la misma actriz, que afrontando un nuevo papel se encarga de dar otro tipo de respuestas a las preguntas que le son demandadas. La escena vuelve a desvelarse como escena prepornográfica que por convención genérica debiera desembocar de manera inminente en un acto sexual. Sin embargo, el hecho de saber que no estamos presenciando una película pornográfica, unido a la interrupción de la primera escena de casting que se ha mostrado, impide que esta secuencia pueda verse como pre-pornográfica. Tal y como señalan Barba y Montes:

En tanto que mi excitación ante el acontecimiento pornográfico no se produzca, ese acontecimiento no es pornográfico, sino cómico, ridículo, inmoral, desagradable, o inocuo. Es muy habitual escuchar que la pornografía resulta "aburrida", "ridícula" o "inverosímil". La respuesta más apropiada sería hacer comprender a quienes tal cosa afirman que, sencillamente, lo que ha sucedido es que no han visto pornografía en absoluto [...] Y no la han visto, entre otras razones, porque como observadores han negado dos principios básicos para que el acontecimiento pornográfico se produzca: La conciencia prejudicativa de la revelación por un lado, y el compromiso de la excitación por el otro (Barba, Montes, 44).

Es decir, que o bien tomamos la imagen como pornográfica, con el erotismo y la excitación que ello conlleva, o bien evitamos el acontecimiento sexual y la tomamos como un simple objeto estético. Esta decisión se aplica por igual a las secuencias prepornográficas, las cuales, una vez son descontextualizadas del conjunto para el que nacieron, pierden el propósito de su narrativa. En este sentido After Eden supone una exploración directa de este tipo de escenas, filmadas ex profeso para el film, pero que bien podrían estar sacadas de alguno de los videos que la actriz ha protagonizado en la vida real. Se intercalan así un 
conjunto de escenas que repiten una serie de patrones conocidos que juegan en torno a los roles de poder empleados tanto por el realizador como por la actriz con el objetivo de cautivar al espectador masculino, que precisamente visualiza con atención su contenido porque desea caer en las redes de la imagen pornográfica.

Siguiendo con esto, el tercer y último segmento de la película -llamarlo desenlace cuando no hay progresión dramática sería erróneo-, nos plantea un doble juego que se suma al que el espectador está viviendo. El protagonista, con el apodo de Adán, obsesionado con la actriz pornográfica, decide pagar sus servicios sexuales citándola en un lujoso hotel. Esta acude allí para enfrentarse al joven, que nervioso, propone grabar el encuentro con su cámara digital. Se crea así una nueva aproximación al gonzo en la que la actriz, que hace de sí misma, no deja de interpretar el papel de actriz porno ante el excitado fan con el que va a mantener relaciones.

Esta secuencia es una réplica de la serie Tonights Girlfriend, cuyo argumento, dentro de los parámetros del cine de calentamiento y siempre en clave documental, desarrolla el mismo motivo en todos sus capítulos: Una conocida actriz porno que acude a una lujosa habitación de hotel en la que un actor desconocido, que interpreta a un hombre con dinero y ganas de pasarlo bien, paga sus servicios, satisfaciendo así gracias al capital la fantasía de la accesibilidad de una deseada mujer de anatomía perfecta. Como puede comprobarse, esta concepción pornográfica de nuevo parte de la dicotomía hombre que manda, mujer que se ofrece, despejándose paulatinamente por medio de órdenes directas el erotismo inicial para dar paso a la explicitud sexual. La pornografía como fantasía se desmitifica al presentarse como una realidad documental perfectamente accesible. La figura de la celebridad porno es susceptible, al igual que en el caso de las Pilladas de Torbe, de convertirse en prostituta por la cantidad de dinero adecuada, tal y como suelen reflejar los primeros instantes de este tipo de secuencias que reflejan este pago. Acto seguido, la cámara asiste a la constitución del objeto de deseo, con la actriz duchándose, maquillándose y vistiéndose frente a cámara en el baño de la habitación antes de pasar a la acción.

Estamos en definitiva ante una pieza de ficción, disfrazada con máscara de documental, que busca promover una serie de estereotipos conocidos de sobra por el espectador al que van dirigidos de cara a culminar el proceso narrativo de la escena de la cópula que la sigue. Por el contrario, el acto sexual en sí mismo, si bien da continuación al juego de roles creado en la primera parte, es visto por el catedrático Roman Gubern como la verdadera esencia documental del cine pornográfico:

Catalogar al cine porno duro como documental fisiológico no constituye una exageración. El cine porno duro es, antes que nada, un documental fisiológico sobre la felación, el cunnilingus, la erección, el coito y la eyaculación. La eyaculación no es un acto de interpretación dramática, sino un acto reflejo. Si la actuación de todo actor/actriz bascula entre la interpretación y la vivencia, entre la simulación y la autenticidad, en el actor masculino del género, y en las escenas sexuales, el segundo polo debe ser netamente predominante, pues una erección y una eyaculación son antes una vivencia que un acto de interpretación (Gubern, 2005: 27). 


\section{Conclusiones}

La validez y efectividad del artefacto pornográfico audiovisual respecto a su teleológico fin requiere ante todo la labor activa del espectador que visualiza la escena. Así pues, de cara a buscar un mayor realismo, la conocida como pornografía gonzo o POV ha desarrollado toda una serie de técnicas propias del cine documental con el propósito de mostrar un objeto sexual que dé imagen de veracidad, fomentando además la identificación del espectador con el actor principal de cara a aumentar la excitabilidad de este. Algunas de estas técnicas son la utilización de la cámara en mano, la reducción del uso de cortes, el empleo de tomas largas, o que sea el propio actor el que ejerce de cámara filmando la escena.

En esta pornografía, que es producida fundamentalmente por hombres y dirigida a un público masculino, es predominante la cosificación del cuerpo femenino. Sin embargo, esta cosificación no aparece espontáneamente en el momento de la cópula, la cual contiene a menudo prácticas extremas y denigrantes de cara a fomentar su atractivo. En su lugar, se prepara durante los instantes prepornográficos al ofrecer toda una serie de representaciones y relaciones de poder en torno a la creación genérica del hombre (que primero valora y luego demanda) y de la mujer (que proporciona). Relaciones y estereotipos que se mantienen en la escena sexual y que son la fuente de buena parte de las críticas feministas que la pornografía recibe.

Así pues, este tipo de secuencias prepornográficas muestran una serie de configuraciones que se repiten a lo largo de la pornografía gonzo, y que pueden dividirse por lo general en dos grandes bloques: por un lado el de escenas-videoclips, dedicados a una estrella conocida y que no dejan de ser una muestra de sus atributos sexuales, y por el otro el de escenas de calentamiento, consistentes en entrevistas en las que la actriz se pone al servicio del actor que graba la secuencia, respondiendo todas sus cuestiones y quitándose la ropa o mostrando partes de su cuerpo bajo sus órdenes. Dentro de esta categoría es posible identificar varios subgéneros: entrevistas a estrellas conocidas sobre desafíos sexuales, encuentros casuales en la calle con "desconocidas", castings de aspirantes a actrices, o la contratación de servicios sexuales de las actrices como scorts.

A través de los parámetros estilísticos de la no ficción, la pornografía gonzo genera toda una serie de narrativas previas al acto sexual que no tienen ningún valor más allá de la función de provocar la estimulación sexual del espectador masculino al que va destinado. Así, estas escenas de planteamiento son las que en primer lugar generan una situación de desigualdad que favorece al hombre, cuya situación de dominio, más allá de tener la cámara y poder elegir qué mostrar, es explicitada a menudo como la posesión de algún elemento que la actriz necesita y que puede intercambiar por sexo, habitualmente un trabajo o dinero. De esta forma, mientras que la pornografía recibe críticas encontradas por las representaciones sexuales que presenta, cabe abrir al análisis crítico todo lo que antecede a la filmación del acto sexual. Se descubren así más fundamentos a favor de aquellos espectadores que acusan a estos constructos de irreales y perpetuadores de una determinada violencia contra la mujer como primer paso para demandar una pornografía de corte alternativo que no refleje estas desigualdades desde su concepción. 


\section{Bibliografía}

ALARIO GAVILÁN, MÓNICA (2018). La influencia del imaginario de la pornografía hegemónica en la construcción del deseo sexual masculine prostituyente: un análisis de la demanda de prostitución. Asparkía. Investigació Feminista, (33), 61-79.

ALARIO GAVILÁN, MÓNICA (2019). La reproducción de la violencia sexual: un análisis de la masculinidad hegemónica y la pornografía. En M. Blanco \& C. Sainz de Baranda (Eds.), Investigación joven con perspectiva de género IV (pp. 55-66). Getafe: Instituto de Estudios de Género, Universidad Carlos III de Madrid.

ATTWOOD, FEONA (2004). Pornography and objectification: re-reading "the picture that divided Britain". Feminist media studies, 5 (1), 7-19.

BARBA, ANDRÉS, MONTES, JAVIER (2007). La ceremonia del porno. Barcelona: Anagrama. BERGER, JOHN (1972). Ways of seeing. Londres: Penguin Books.

BIASIN, ENRICO, ZECCA, FEDERICO (2009). Contemporary audiovisual pornography: Branding strategy and gonzo film style. Cinéma \& Cie: International Film Studies Journal, 10 (12), 139-145.

BLACK, JOEL (2002). The Reality Effect: Film Culture and the Graphic Imperative. Nueva York: Routledge.

BORDIEU, PIERRE (2014). La dominación masculina. Barcelona: Anagrama.

BOYLE, KAREN (2006). The boundaries of porn studies: on Linda Williams' porn studies. New Review of Film and Television Studies, 4 (1), 1-16, http://dx.doi. org/10.1080/17400300600577286

BRAIDOTTI, ROSI (2002). Body-Images and the Pornography of Representation. En K. Lennon \& M. Whitford (Eds.), Knowing The Difference. Feminist perspectives in epistemology (pp. 17-30). Londres: Taylor \& Francis.

BRODESCO, ALBERTO (2016). POV to the people: online discourses about gonzo pornography. Porn Studies, Vol. 3 (4), 362-372.

BROWNMILLER, SUSAN (1981). Contra nuestra voluntad: hombres, mujeres y violación. Barcelona: Planeta.

BUCKLAND, WARREN (2003). The cognitive semiotics of film. Cambridge: Cambridge University Press.

COSTA, JORDI (2006). El sexo que habla: el porno español explicado por sí mismo. Madrid: Aguilar.

CRABBE, MAREE \& CORLETT, DAVID (2010). Eroticizing Inequality: Technology, Pornography and Young People. Redress, 20 (1), 1-6.

DEKESEREDY, WALTER (2005). Critical Criminological Understandings of Adult Pornography and Woman Abuse: New Progressive Directions in Research and Theory. International Journal for Crime, Justice and Social Democracy, Vol 4, 4-21, https://doi. org/10.5204/ijcjsd.v4i4.184

DEKESEREDY, WALTER, HALL-SANCHEZ, AMANDA. (2014). Pornography and violence against woman in the heartland: Results from a rural southeast Ohio Study. Paper presented at the anual meetings of the American Society of Criminology, San Francis- 
co. Recuperado de https://www.researchgate.net/publication/303470751_Adult_ Pornography_and_Violence_Against_Women_in_the_Heartland_Results_From_a_Rural_Southeast_Ohio_Study

DÍAZ-BENÍTEZ, MARÍA ELVIRA (2013). El quehacer porno en la construcción de imágenes de espectacularidad. Memoria y sociedad, 17 (34), 92-109.

DINES, GAIL (2010). Pornland: How porn has hijacked our sexuality. Boston: Beacon Press. DWORKIN, ANDREA (1989). Pornography: Men possessing Women. Nueva York: Putnam. GUBERN, ROMÁN (2005). La imagen pornográfica y otras patologías de la imagen. Barcelona: Anagrama.

HARMON, P. A, CHECK J. V.P. (1989) The role of pornography in woman abuse. Toronto: LaMarsh Research Program on Violence and Conflict Resolution, York University.

JOST, FRANÇOIS (2003). Realtà/Finzione. L'impero del falso. Milano: Il Castoro.

KUHN, ANNETTE (1994). The Power of the Image: Essays on Representation and Sexuality. Londres: Routledge.

LEHMAN, PETER (2006). A dirty little secret. Why teach and study pornography?. En P.Lehman (Ed.), Pornography: Film and culture. (pp. 244-257). New Brunswick: Rutgers University Press.

LLOPIS, MARÍA (2010). El postporno era eso. Santa Cruz de Tenerife: Melusina.

LUST, ERIKA (2010). Good Porn. A woman's guide. Berkeley: Seal Press.

MACKINNON, CATHARINE (1987). Feminism Unmodified. Boston: Harvard University Press. MACKINNON, CATHARINE (1995). Hacia una teoría feminista del estado. Madrid: Cátedra. MAINA, GIOVANNA, ZECCA, FEDERICO (2016) Harder than fiction: the stylistic model of gonzo pornography, Porn Studies, 3 (4), 337-350, DOI: 10.1080 / 23268743.2016.1241161

MALEM SEÑA, JORGE FRANCISCO (1992). Pornografía y feminismo radical. Doxa, 12, 177211.

MARTÍN, SANZ, ÁLVARO (2018). Belleza e irrealidad en la nueva pornografía feminista: la imagen pornográfica de Erika Lust. Fotocinema. Revista Científica de Cine y Fotografía, 17, 343-365.

MARZANO, MARIA MICHELA (2006). La pornografía o el agotamiento del deseo. Buenos Aires: Manantial.

MCNAIR, BRIAN (2002). Striptease culture. Sex, media and the democratization of desire. Londres: Routledge.

MILLER, RUSSELL (1984). Bunny: The real story of Playboy. Londres: Michael Joseph.

MULVEY, LAURA (2001). Placer visual y cine narrativo. En W. Brian (Ed.), Arte después de la modernidad. Nuevos planteamientos en torno a la representación (pp. 365-377). Madrid: Ediciones Akal.

OGIEN, RUWEN (2005). Pensar la pornografía. Barcelona: Paidós.

PAASONEN, SUSANNA (2006). Email from Nancy Nutsucker. European Journal of Cultural Studies, 9 (4), 403-420.

PRADA PRADA, NANCY (2010). ¿Qué decimos las feministas sobre la pornografía? Los orígenes de un debate. La manzana de la discordia, 5 (1), 7-26. 
PRECIADO, BEATRIZ [PAUL B.]. (2010). Pornotopía. Arquitectura y sexualidad en "Playboy" durante la guerra fría. Barcelona: Anagrama.

PURCELL, NATALIE (2012). Violence and the Pornographic Imaginary: The politics of sex, gender, and aggression in Hardcore Pornography. Nueva York: Routledge.

SHOPE, JANET HINSON. (2004). When words are not enough: The search for the effect of pornography on abused woman. Violence Against Women, 10 (1), 56-72.

SEGAL, LYNNE (1992). Introduction. En L. Segal \& M. McIntosh (Eds.) Sex Exposed: Sexuality and the Pornography Debate (pp.1-11). Nueva Jersey: Rutgers University Press.

TORRES, DIANA J. (2011). Pornoterrorismo. Pamplona: Txalaparta.

WEEKS, JEFFREY (2005). Sexuality. Nueva York: Routledge.

WILLIAMS, LINDA (1999). Hard Core: Power, pleasure and the "Frenzy of the visible". Berkeley: University of California Press.

WILLIAMS, LINDA (1999b). Fetichismo y hard core: Marx, Freud y el "money shot". Erreakzioia/ Redacción, 9, 58-65.

ŽIŽEK, SLAVOJ (1997). The plague of fantasies. Londres: Verso. 